Canadian

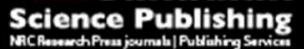

Canadian Journal of Civil Engineering Revue canadienne de génie civil

\title{
Application of Curing Compounds on Concrete Pavements
}

\begin{tabular}{|r|l|}
\hline Journal: & Canadian Journal of Civil Engineering \\
\hline Manuscript ID & cjce-2016-0499.R1 \\
\hline Manuscript Type: & Article \\
\hline Date Submitted by the Author: & 22-Feb-2017 \\
\hline Complete List of Authors: & $\begin{array}{l}\text { Tiznobaik, M. ; University of Manitoba, Civil Engineering } \\
\text { Bassuoni, Mohamed; University of Manitoba, Civil Engineering }\end{array}$ \\
\hline Keyword: & Concrete curing, Roads \& highways, Field testing \& monitoring \\
\hline \multicolumn{2}{|l}{} \\
\hline
\end{tabular}

SCHOLARONE ${ }^{\text {M }}$

Manuscripts 


\section{Application of Curing Compounds on Concrete Pavements}

M. Tiznobaik, M.Eng., EIT.

Ph.D. Candidate, Department of Civil Engineering, University of Manitoba

15 Gillson Street,

Winnipeg, MB, Canada, R3T 5V6

E-mail: umtiznob@myumanitoba.ca

M. T. Bassuoni, Ph.D., P.Eng. (Corresponding Author)

Associate Professor, Department of Civil Engineering, University of Manitoba

15 Gillson Street,

Winnipeg, MB, Canada, R3T 5V6

Phone: (204) 272-1512,

E-mail: $\underline{\text { mohamed.bassuoni@umanitoba.ca }}$ 


\begin{abstract}
The concrete hardening process should take place in a manner that provides optimum hydration development, which can be achieved through proper curing practices. Since curing of concrete is essential at controlling its mechanical and durability performance during service, the aim of this research was to assess the effect of different curing compound applications on the behavior of field pavement, and thus projecting its long-term durability. The study involved experiments on cores extracted from recently constructed pavement sections in comparison to corresponding specimens produced from similar concrete under laboratory conditions. Absorption, rapid chloride penetrability, thermogravimetry, mercury intrusion porosimetry, and scanning electron microscopy tests were conducted on cores/specimens to study the effect of the different curing compound applications. The overall trends indicate that applying a thorough coat of curing compound is essential to ensure moisture retention in concrete for efficient hydration reactions and microstructural development.
\end{abstract}

Keywords: Concrete curing, Field testing \& monitoring, Roads \& highways 


\section{Introduction}

The aspect of curing involves keeping concrete saturated as much as possible, till water-filled space in fresh concrete has been occupied by cement hydration products to the desired extent (Neville 2011). This can be done by maintaining a satisfactory level of moisture content (RH above 90\%) and temperature in concrete for a period of time (preferably seven days or more) immediately following placing and finishing procedures to attain the desired properties. For example, properly cured concrete should achieve target strength, abrasion resistance, volumetric stability, water tightness and resistance to freezethaw cycles. Water curing of concrete is applied by different methods such as ponding, immersion, fogging and wet coverings; however, membrane (e.g. with curing compounds) is considered as the most efficient and practical procedure for fast construction of concrete elements such as floors, pavements and sidewalks (Mehta and Monteiro 2014). Concrete pavements are typically cured by membrane-forming curing compounds that usually consist of a resin or wax dissolved in a solvent or emulsified in water. They are applied to pavement surface, and by evaporation of the solvent, the wax or resin forms an impermeable membrane to help retaining moisture in concrete. In North American standards for concrete (e.g. CSA A23.1/A23.2 2014; ACI 308R-16 2016), curing compounds are specified by AASHTO M148 (2005) and ASTM C309 (2011). Applying an adequate rate of curing compounds and providing a uniform coverage onto concrete are required to ensure efficiency of the curing process (Vandenbossche 1999).

Concrete pavements are particularly vulnerable to moisture loss via evaporation during the hardening process due to their high surface-to-volume ratio. Improper curing of concrete causes insufficient hydration of the cementitious matrix, which is associated with performance risks during service; for example, inadequate curing of concrete pavements may lead to forming a continuous pore structure within the surface, which facilitates the penetrability of moisture carrying aggressive agents (e.g. deicing salts), and thus provoking durability issues such as surface scaling and frost damage (Marchand et al. 1994; Bouzoubaâ et al. 2011). Moreover, drying of concrete surface at early-age may lead to a network of plastic and drying shrinkage cracks, which adversely affect the long-term performance of concrete (Bentz and Jensen 2004). In addition to the mixture design of 
concrete, the prevailing conditions in the field including the relative humidity, temperature and wind velocity affect the evaporation rate of moisture from concrete. It was reported that reduction of the relative humidity during the curing process from 100 to $94 \%$ led to a marked increase of the water absorption capacity of concrete (Ho et al. 1989), implicating the alteration of microstructure. If the external relative humidity falls below $80 \%$ during the initial curing process, the proportion of macro-pores (larger than $0.1 \mu \mathrm{m}$ ) in the hydrated paste may significantly increase and cause higher penetrability of concrete (Mehta and Monteiro 2014).

Numerous studies reported the effect of different curing methods (e.g. water curing, covering with plastic sheets or curing compound) on hardened properties of concrete. (e.g. Marchand et al. 1994; Nassif et al. 2005; Ibrahim et al. 2013). Curing compounds can efficiently maintain the moisture content, increase the degree of cement hydration and decrease sorptivity of the near-surface layer of concrete (e.g. Ibrahim et al. 2013). Also, curing compounds may lead to less plastic and drying shrinkage of concrete (Al-Gahtani 2010). It has been reported that premature deterioration of concrete pavements, especially at joint locations are strongly linked to the penetrability of concrete (e.g. MDOT 1996; Chen et al. 2011; Liu et al. 2014), which is highly affected by the efficacy of curing practices. In North America, there are recommendations to apply curing compounds at a rate of 1.5 to 2 times the normal rate specified by the manufacturer in repair applications of concrete pavements (e.g. GPDR-COW 2015) with the perception that this practice substantially improves the curing efficiency of repair concrete, and thus it may be applied to concrete pavements during the construction process. Also, it is recommended that the specified rate of application can be achieved by two coats (each one applied at half the specified rate) to attain a uniform application of curing compound on concrete (TxDOT 2004). Yet, there are scarce field data on the effect of applying different rates or multiple coats of curing compounds on the quality of concrete, especially with respect to concrete pavements. Hence, the degree of curing efficiency of applying multiple coats of curing compounds on concrete pavements, and whether this practice can significantly enhance their durability properties remain uncertain. This is a critical question to a number of transportation agencies including Public Works Department, Winnipeg (Manitoba, Canada) 
linked to changing current construction specifications and associated with considerable increase of initial construction costs. Hence, the motive for this research is to investigate the effect of three different curing compound applications (no curing compound, one coat of curing compound, and two coats of curing compound) on the behavior of concrete pavements in terms of their resistance to infiltration of fluids and microstructural evolution to project their long-term durability. The project consisted of macro- and micro-scale experiments on cores extracted from recently constructed pavement sections in Winnipeg, Manitoba, Canada in comparison to corresponding specimens cast from similar concrete under laboratory conditions. This collaborative research study between the City of Winnipeg (COW) and University of Manitoba ( $U$ of $M)$ was conducted in order to informatively guide the curing practices incorporated in the COW construction specifications for concrete pavements.

\section{Experimental Program}

\subsection{Materials and mixtures}

For the field pavement sections, the COW specified a ready mix concrete with target performance of $35 \mathrm{MPa}$ and a class of exposure C-2 (plain concrete subjected to chlorides and freezing-thawing) according to CSA A23.1 (2014). Also, the same type of concrete was delivered to the $\mathrm{U}$ of $\mathrm{M}$ in order to prepare the laboratory specimens. The binder comprised General Use (GU) portland cement and fly ash (Class F), as a supplementary cementitious material (SCM), meeting the current requirements of CSA A3001 (2013), and the water-to-cementitious materials ratio (w/cm) was in the range of 0.36 to 0.38 . The COW construction specifications for jointed plain concrete pavements (CW3310-R17 2015) permit replacement of GU cement with up to $15 \%$ Class F fly ash. A chemical air-entraining admixture complying with ASTM C260 (2010) was used in concrete to achieve a fresh air content of 5 to $8 \%$. Also, a high-range water reducing agent complying with ASTM C494/C494M (2013) was used to obtain a target slump of 30 to 70 $\mathrm{mm}$ for slip forming. Due to a confidentiality agreement between the $U$ of $M$ and the concrete supplier, the specific proportions of the concrete mixture design cannot be disclosed. The curing compound applied was white in color and made of high-grade 
hydrocarbon resins in a water-based emulsion conforming to ASTM C309 (2011) Types 1, 2 and 1-D, Class B.

\subsection{Field pavement sections and laboratory specimens}

Three pavement sections were cast in an urban arterial road at the central area of Winnipeg, Manitoba. The pavement sections consisted of a $150 \mathrm{~mm}$ thick jointed plain concrete pavement with a slab width of $3.70 \mathrm{~m}$ on a granular base (Figure 1). The test sections comprised a two-way undivided road with one traffic lane and one parking lane in each direction. The speed limit in this area is $50 \mathrm{~km} / \mathrm{h}$ and the average week-day daily traffic is 12,800 vehicles over the two lanes of traffic with $2 \%$ trucks and buses. The pavement in the test location is expected to be subjected to large temperature changes, as the maximum and the minimum air temperatures during the last 10 years were $+36^{\circ} \mathrm{C}$ and $36^{\circ} \mathrm{C}$, respectively.

The placement, consolidation, finishing and curing procedures of the pavement sections complied with the COW construction specification (CW3310-R17 2015). Placement of concrete was done via the discharge chute of ready-mix concrete trucks for continuous supply to the slipform paver, which consolidated fresh concrete using a series of internal vibrators. This was immediately followed by finishing with bull floats and wooden trowels for fine tuning and final surfacing. Three pavement sections received different types of curing: no curing, one coat of curing compound, and two coats of curing compound, referred to hereafter as $\mathrm{NC}, 1 \mathrm{CC}$ and $2 \mathrm{CC}$, respectively. Shortly (30 to $45 \mathrm{~min}$ ) after the finishing operations, the first coat of curing compound was applied by labor, using portable sprayers on the designated $1 \mathrm{CC}$ and $2 \mathrm{CC}$ sections. Each coat of curing compound was applied at the rate of $0.231 / \mathrm{m}^{2}$ according to the manufacturer's specifications. In addition, visual inspection was mandated by the COW specifications to cover any left out spots "holidays", where the surface of the pavement sections was uniformly white in color. The pavement slabs were saw-cut eight hours after casting to establish the contraction joints with the dimensions of $3 \mathrm{~mm}$ wide and $40 \mathrm{~mm}$ deep. For the $2 \mathrm{CC}$ section, the second coat of curing compound was applied immediately after saw-cutting. The second cut for joint sealing took place three weeks after the initial saw-cut with the dimensions of $10 \mathrm{~mm}$ wide and $30 \mathrm{~mm}$ deep. The joints were subsequently filled with a backer rod and sealed. At 
28 days, forty eight cores $100 \mathrm{~mm}$ in diameter and twenty four cores $75 \mathrm{~mm}$ in diameter were extracted from the pavement slabs. Eight cores were used for each test according to Table 1; four cores were obtained from the center of the slab (mid-slab). For ASTM C1585 (2013) and C1202 (2012) tests, the other four cores were extracted from areas immediately right (two cores) and left (two cores) of transverse joints to obtain full cores. Comparatively, for the COW absorption test (COW-2013-01 2013), the other four cores were obtained directly at transverse joints (split cores). Figure 2 illustrates the locations of the cores extracted from the field sections.

Laboratory specimens were prepared from the same ready mix concrete delivered by the same supplier. Thus, the effect of standard (laboratory) casting relative to actual field practice on the transport properties of concrete (i.e. 'controlled' vs. 'uncontrolled') was taken into account. This is to ensure that any variation in the trends and microstructure of concrete would be originating from the curing method rather than the field practice or ambient conditions (e.g. effect of evaporation rate in the field). Thirty six $100 \mathrm{~mm} \times 200$ $\mathrm{mm}$ concrete cylinders and nine $75 \mathrm{~mm} \times 150 \mathrm{~mm}$ concrete cylinders were cast in PVC moulds. The cylinders were filled in two layers, where each layer was compacted 25 times by a standard tamping rod according to ASTM C192/C192M (2013). The top surface of specimens were cured in a similar way to the field pavement sections (i.e. NC, 1CC and $2 \mathrm{CC}$ ), and they were kept in moulds for 28 days (to simulate center of slab cores) under laboratory conditions $\left(23 \pm 2^{\circ} \mathrm{C}\right.$ and $\left.55 \pm 5 \% \mathrm{RH}\right)$. The testing scheme was similar to that of the field cores (Table 1), except that three replicates were used for each test and curing application, as the cylinders were prepared in a standard way.

\subsection{Tests}

\subsubsection{Strength and absorption tests}

The compressive strength of both field and laboratory concretes were tested according to ASTM C39/C39M (2014), the results were in the range of 41 to $43 \mathrm{MPa}$ meeting the COW requirements for strength. The rate and total absorption were determined for concrete specimens according to ASTM C1585 (2013). At 28 days, the top skin ( 3 $\mathrm{mm}$, including the curing compound layer) of the cylindrical specimens was removed and the adjacent $50 \mathrm{~mm}$ thick discs were cut as the test specimens. Also, COW absorption test 
(absorption by immersion; COW-2013-01 2013) was conducted on both laboratory specimens and field cores. After 28 days, the surface of concrete was gently cleaned with a brass brush to remove the curing compound layer, and $50 \mathrm{~mm}$ thick slices were cut from cylindrical specimens and cores. For the laboratory specimens and cores extracted from the center of slab, top and bottom $50 \mathrm{~mm}$ (baseline) slices were obtained, whereas only the top $50 \mathrm{~mm}$ part was cut from the cores obtained at the joints, as required by the test procedures. The concrete discs were placed in a sealed desiccator under vacuum pressure $(\sim 85 \mathrm{kPa})$ for six hours. Subsequently, the specimens were removed from the desiccator and each one dried out with compressed air. Afterwards, the initial mass of the dried specimens to the nearest $0.01 \mathrm{~g}$ was recorded. Each specimen was immersed in deionized water for $60 \pm 3 \mathrm{~s}$, and then excess water was blotted off and the wet mass of the specimen was recorded within $25 \mathrm{~s}$ to the nearest $0.01 \mathrm{~g}$. The amount of water absorbed into concrete was determined by subtracting the dry mass from the wet mass and converted to a percent of the wet mass of the specimen. The percentage of water absorption is important because the actual volume of specimens may vary due to coring operations, and it was calculated by:

$$
W A=\frac{\left(W_{g}-D_{g}\right)}{W_{g}} \times 100
$$

where $W A$ is the percentage of water absorption of concrete, $W_{g}$ and $D_{g}$ are the wet mass and dry mass of concrete test specimens in g, respectively. To evaluate the efficiency of curing of concrete, the absorption of top part for each location was compared to the absorption of the bottom slices of the center of slab. The bottom slices of the center of slab are considered as the baseline for curing efficiency in the field according to COW-2013-01 (2013).

\subsubsection{Rapid chloride penetrability test (RCPT)}

The interconnectivity of pore system in concrete specimens/cores was assessed by the rapid chloride penetrability test (ASTM C1202 2012). At 28 days, the surface skin ( $\sim 3$ $\mathrm{mm}$ ) from the top and bottom of cylindrical specimens was removed to reach a clear surface, and the top $50 \mathrm{~mm}$ thick discs were cut as the test specimens. Since physical observation provides better representation of the penetration of chloride ions into concrete, 
the physical penetration depth of chloride ions was measured immediately after the completion of the test by spraying $0.1 \mathrm{M}$ silver nitrate solution on the surface of equally split discs (Bassuoni et al., 2006). The discs were allowed to set under fluorescent light for about 15 minutes to obtain the whitish precipitate of silver chloride. Five penetration depths (every $20 \mathrm{~mm}$ ) were measured on each half disc (i.e. 10 readings per specimen) to calculate the average penetration depth for each specimen. To account for the possible heat effect of RCPT and physical features of the pore structure, the migration coefficient of concrete was calculated by (NT BUILD 492 1999):

$$
D=\frac{0.0239(273+T) L}{(V-2) t}\left(x_{d}-0.0238 \sqrt{\frac{(273+T) L x_{d}}{V-2}}\right)
$$

where $D$ is the non-steady-state migration coefficient in $\mathrm{m}^{2} / \mathrm{s}\left(\times 10^{-12}\right), V$ is the applied voltage in $\mathrm{V}, T$ is the average value of initial and final temperatures in the anolyte solution in ${ }^{\circ} \mathrm{C}, L$ is the thickness of the specimen in $\mathrm{mm}, x_{d}$ is the average value of penetration depth in $\mathrm{mm}$, and $t$ is time in $\mathrm{h}$.

\subsubsection{Thermogravimetry (TG), mercury intrusion porosimetry (MIP) and microscopy tests}

The effect of different curing compound applications on the development of microstructure in concrete was assessed by thermogravimetry (TG), mercury intrusion porosimetry (MIP) and backscattered scanning electron microscopy (BSEM). Samples for TG tests were prepared by crushing chunks around 4-7 $\mathrm{mm}$ in size taken from the top 15 $\mathrm{mm}$ of the laboratory concrete cylinders (prepared with GU and a maximum of $15 \%$ fly ash) and grinding them to fine powder passing sieve \#200 (75 $\mu \mathrm{m})$. The TG tests were conducted using a heating rate of $10^{\circ} \mathrm{C} / \mathrm{min}$ at $1,3,7$ and 28 days. The content of portlandite (calcium hydroxide) was calculated by determining the drop in the percentage mass of TG curves at a temperature range of 400 to $450^{\circ} \mathrm{C}$ and multiplying it by 4.11 (ratio of the molecular mass of portlandite to that of water). To capture the characteristics of pore structure, the MIP technique was conducted on field concrete samples at 28 days. Small pea-sized chunks were taken from at least two concrete cylinders and were used as test samples for MIP (Kumar and Bhattacharjee 2003; Said et al. 2012). These chunks were around 4-7 $\mathrm{mm}$ in size, and carefully selected so that large aggregates were not included. 
These chunks were taken from the top $15 \mathrm{~mm}$ of the concrete cores $(75 \mathrm{~mm}$ cores) extracted at the center of slabs and joints (split cores). The samples were oven dried for $72 \mathrm{~h}$ at a temperature of $55 \pm 2{ }^{\circ} \mathrm{C}$; they were then kept in a desiccator containing calcium sulphate for $24 \mathrm{~h}$. This method of drying - using a lower temperature for a longer period was adopted to avoid decomposition of calcium silicate hydrate $(\mathrm{C}-\mathrm{S}-\mathrm{H})$ and formation of micro-cracks, which may occur at high temperatures. The contact angle and the surface tension of mercury were taken as $130^{\circ}$ and 485 dynes/cm, respectively (Shi and Winslow 1985; Said et al. 2012). To complement the trends observed in the various tests, BSEM was conducted on polished thin sections from the field cores extracted at the center of slabs after 180 days. Slices were cut from the top part $(25 \mathrm{~mm})$ of cores; they were then dried and impregnated with a low-viscosity epoxy resin under vacuum pressure and polished by successive diamond surface-grinding to a thickness of about $50 \mu \mathrm{m}$. The sections were coated then with carbon to enhance the conductivity for the BSEM imaging.

\subsection{Statistical analysis}

The results of absorption and RCPT were statistically evaluated by the Analysis of Variance (ANOVA) method at a significance level $(\alpha)$ of 0.05 . ANOVA is a statistical model used to analyze the differences between group means and their variation among and between groups. The variance of a specific parameter is separated into components attributed to different sources of variation. ANOVA tests the hypothesis that the means of several groups are comparable via a $t$-test, and it can generalize the test to more than two groups. According to ANOVA, exceeding the $F_{c r}$ for an $F$-distribution density function indicates that the variable tested has a statistically significant effect on the average results (Montgomery 2012). The ANOVA results were further statistically evaluated by Tukey's post hoc test (Tukey's test), when applicable, to declare pairwise comparisons between the means of each two groups. Tukey's post hoc test declares two means significantly different if the absolute value of their sample differences exceeds a critical range, $q_{c r}$ (Montgomery 2012). 


\section{Results and Discussion}

\subsection{Environmental conditions}

During casting the field sections, the average ambient air temperature and relative humidity were $20^{\circ} \mathrm{C}$ and $78 \%$, respectively, with a wind velocity of less than $31 \mathrm{~km} / \mathrm{h}$ (Figure 3). The measured temperature of concrete pavement was about $19^{\circ} \mathrm{C}$. Under these weather conditions, the moisture evaporation rate at the concrete surface was estimated at $0.25 \mathrm{~kg} / \mathrm{m}^{2} / \mathrm{h}$ according to the chart of the Canadian standard CSA A23.1/A23.2 (2014). This value was well below the critical evaporation rate $\left(0.50-0.75 \mathrm{~kg} / \mathrm{m}^{2} / \mathrm{h}\right)$ stipulated by ACI 308R-16 (2016) mainly to minimize the risk of surface drying and plastic shrinkage cracking. Also, four rainy days were recorded during the first week of casting (Figure 3). Laboratory specimens were cast under standard room conditions $\left(21^{\circ} \mathrm{C}\right.$ and $\left.50 \% \mathrm{RH}\right)$ with a negligible wind velocity, and the concrete temperature measured was about $18^{\circ} \mathrm{C}$. These conditions led to a surface moisture evaporation rate of $0.20 \mathrm{~kg} / \mathrm{m}^{2} / \mathrm{h}$. Hence, it can be deduced that the field concrete sections originally planned to receive no treatment in terms of curing compound application (NC) were beneficially affected by the prevailing climatic conditions (low rates of evaporation, high relative humidity and rainfall, [Figure 3]).

\subsection{Absorption tests}

The behavior of concrete exposed to aggressive environments (e.g. deicing salts and freezing-thawing cycles) depends on the mode of transport of moisture and ionic species through the pore system, which indicates the ease of saturation of concrete. Hence, assessing the transport properties of concrete is critical to concrete pavements. Absorption, which is defined as the fluid uptake into the surface of concrete through capillary action/suction (Mehta and Monteiro 2014) is one of the key transport properties, as it implicates the porosity of concrete surface as well as the general characteristics of pore structure. This transport mechanism is a function of the surface tension of the penetrating fluid with capillary walls and moisture state in the pore system (dry or partially dry). The ASTM C1585 absorption results are shown in Table 2 and Figure 4. The initial and secondary rates of absorption for the laboratory and field specimens were in the narrow ranges of $1.0 \times 10^{-3}$ to $1.1 \times 10^{-3} \mathrm{~mm} / \widehat{ }_{\mathrm{s}}$ and $0.3 \times 10^{-3}$ to $0.4 \times 10^{-3} \mathrm{~mm} / \mathrm{V}_{\mathrm{s}}$, respectively, without a distinctive effect of the scheme of curing. However, the general trend of the 
absorption curves shown in Figure 4 indicates reduction (up to 15\%) of the total absorption of concrete with the application of the curing compound (1CC and $2 \mathrm{CC}$ ) relative to $\mathrm{NC}$ (Figure 5). This behavior can be ascribed to the improvement in the hydration process near the top surface of concrete with the application of the curing compound, especially with $2 \mathrm{CC}$, which led to densified microstructure in the hydrated paste and thus reduced the absorption capacity of concrete. However, the ANOVA results for the total absorption results at 8 days for both laboratory and field specimens (summarized in Table 3) showed the effect of the type of curing on the total absorption of concrete to be statistically insignificant. This insignificance is attributed to the overlapping range of results for replicate specimens among the groups tested which can be graphically noted in the range of error bars (standard deviation) depicted in Figure 5. Also, it can be noted that field cores, especially specimens with NC had higher variability of results, which contributed to this insignificance. Overall, the general trend of results highlights the importance of curing in improving the microstructure of concrete, and consequently reducing its absorption capacity.

The results of the COW absorption (by full immersion) test are given in Table 4, and the absorption ratios (top-to-bottom) are shown in Figure 6. It can be noted that the average absorption ratios for the cores from the center of slab were 0.90 and 0.77 for specimens with $1 \mathrm{CC}$ and $2 \mathrm{CC}$, respectively. This might be attributed to the difference in the level of consolidation between the top and bottom layers at the center of slab; in addition, inadequate moistening or excessive drying of this area prior to placement of fresh concrete might have led to some moisture loss from the bottom portion of concrete, and thus influenced the hydration process and in turn the characteristics of pore structure. Irrespective of the method of curing, it can be observed that the absorption values and ratios for the cores extracted at joints are significantly higher than that of corresponding cores extracted from the center of slab or specimens prepared in the laboratory. The higher absorption values of the cores at the joints can be attributed to increasing the exposed surface area in contact with water due to the existence of a groove (vertical walls) in the split cores. The saw cutting process at early- and later- ages could have generated weak planes with micro-cracks in concrete at the joint locations. In addition, creating and 
exposing these surfaces at early-age (final setting) in the absence of curing, may make them susceptible to uncontrolled evaporation. These critical surfaces facilitate absorption, which can result in higher degree of saturation with salt solutions (especially in cold regions where de-icing salts are frequently applied to pavements in winter), and in turn aggravate degradation of concrete in these locations.

For laboratory concrete, the absorption ratios of specimens with $\mathrm{NC}, 1 \mathrm{CC}$ and $2 \mathrm{CC}$ were 1.58, 1.20, 1.05, respectively (Figure 6). ANOVA for the absorption ratios (Table 3) indicates that this trend is statistically significant for specimens prepared in the laboratory and cores extracted from the center of slab. For example, for laboratory specimens, changing the scheme of curing had an $F$ value of 30.32 compared to a critical value $F_{c r}$ of 5.14. These results were further evaluated by Tukey's test to investigate the difference in each possible pair of absorption ratios. Tukey's test declared a significant difference between the curing schemes. According to Table 5, the pairwise comparisons of the absorption ratios were $0.39,0.15$ and 0.53 for curing method pairs of NC versus $1 \mathrm{CC}, 1 \mathrm{CC}$ versus $2 \mathrm{CC}$, and $\mathrm{NC}$ versus $2 \mathrm{CC}$, respectively, compared to $q_{c r}$ of 0.22 . This trend is consistent with the results of field concrete obtained from cores at the center of slab, which signifies the importance of curing in reducing the total absorption of concrete. Complying with the general trend of the ASTM C1585 test, the reduction of absorption capacity of concrete with $1 \mathrm{CC}$ and $2 \mathrm{CC}$ is due to the retention of moisture within the surface layer of concrete, which led to efficient hydration and microstructural development and consequently less water absorption relative to concrete with NC. This suggests that either applying 1CC or 2CC significantly improves the hydration process of concrete.

The absorption ratios for the cores extracted at the joints with $\mathrm{NC}, 1 \mathrm{CC}$ and $2 \mathrm{CC}$ were $1.88,1.72$ and 1.58, respectively (Figure 6). Unlike the case of laboratory specimens and field cores at the center of slab, ANOVA of these results yielded an insignificant effect of the curing scheme on the absorption results at the joints (Table 3). The error bars (standard deviation) of the absorption ratios for the three curing methods at the joints had higher variability, which contributed to this statistical insignificance. Again, this suggested that the COW test had been highly affected by the vertical faces within the groove at joint 
areas, which might have led to this high variability among results. This trend is corroborated by the microstructural results from MIP as discussed later in Section 3.4.

\subsection{RCPT}

The penetrability classification according to ASTM C1202 (2012), physical penetration depth (Bassuoni et al. 2006) and migration coefficient (NT BUILD 492 1999) of concrete were determined after operating the RCPT for 6 hours. The whitish color showing the penetration depth of chloride ions was broadly visible, as for example shown in Figure 7. The passing charges, penetration depths and migration coefficients of laboratory and field concrete are given in Table 6. The classification of chloride ions penetrability of concrete was consistent with the penetration depth results. The passing charges in all concrete specimens were in the range of 1000 to 2000 Coulombs (Table 6); hence, all the specimens were classified as "Low Penetrability" according to ASTM C1202. This conforms to small penetration depths (below $13 \mathrm{~mm}$ ), irrespective of the curing scheme.

The RCPT trends were consistent with that of the absorption tests in the sense that there was generally a slight reduction in the migration coefficient of concrete with $1 \mathrm{CC}$ and $2 \mathrm{CC}$ relative to the corresponding specimens without curing (NC). For example, specimens taken from cores adjacent to joints with $\mathrm{NC}, 1 \mathrm{CC}$ and $2 \mathrm{CC}$ had migration coefficient of $11 \times 10^{-12}, 10 \times 10^{-12}$ and $9 \times 10^{-12} \mathrm{~m}^{2} / \mathrm{s}$, respectively. ANOVA (Table 3 ) for the results of migration coefficients showed that the change in curing method had an insignificant effect on the results. For instance, for laboratory specimens, changing the curing scheme had an $F$ value of 5.12 compared to a critical value $F_{c r}$ of 5.14 . This trend may be attributed to the high quality of this concrete with low w/b (0.36 to 0.38$)$ which led to a dense and disconnected microstructure that discounted ingress of chloride ions. It should be mentioned that specimens from the pavement section without curing compound (NC) were exposed to periods with high relative humidity and intermittent rainfall (natural curing, Figure 3), which improved the efficiency of hydration reactions in a comparable manner to corresponding specimens from sections with $1 \mathrm{CC}$ and 2CC. Correspondingly, laboratory specimens without curing (NC) were kept in the moulds for 28 days and had a limited evaporative surface, which did not affect the evolution of hydration reactions within $50 \mathrm{~mm}$ 
depth from the surface. It should be noted that the groove effect on the results was better captured in the COW absorption test relative to the ASTM C1585 and RCPT due to the locations of the cores extracted (split vs. full cores, Figure 2).

\subsection{Development of microstructure}

The TG results for portlandite $(\mathrm{CH})$ content at different ages are shown in Figure 8. Irrespective of the scheme of curing, the laboratory concrete specimens had a similar pattern characterized by a general increase in the portlandite content followed by a marginal decrease up to 28 days. The former is related to the hydration of cement, while the latter is due to an incipient stage of pozzolanic activity. In this concrete, GU cement was replaced with a low dosage of Class $\mathrm{F}$ fly ash (up to 15\%), and thus significant consumption of portlandite in pozzolanic reactions is unlikely, especially within 28 days (Mehta and Monteiro 2014). The relatively higher portlandite content of specimens with $2 \mathrm{CC}$ at 3, 7 and 28 days allude to better hydration activity; which is consistent with the previous tests.

The results from mercury intrusion porosimetry (MIP) for the field cores obtained from the center of slabs and joints are shown in Table 7, which includes the apparent total porosities, total cumulative intrusions, threshold pore diameters and proportion of micropores (less than $0.1 \mu \mathrm{m}$ ). The MIP tests were done on at least four small chunks extracted from two replicate cores for each section with different curing applications, which were put in the same test compartment (porosimeter). Thus, the results shown in Table 7 can be reasonably considered as the averages of representative populations (Said et al. 2012). The trends of MIP at 28 days conformed to the durability properties (absorption and RCPT) in the sense that the cores at the joint area had a relatively coarser pore structure than that in the corresponding cores at the center of slab; in addition, there was reduction in the total porosity of field cores with $1 \mathrm{CC}$ and $2 \mathrm{CC}$ relative to the corresponding cores without curing (NC) [Table 7]. The threshold pore diameters for cores at center and joint areas with $1 \mathrm{CC}$ and $2 \mathrm{CC}$ were markedly less than those of the corresponding cores with NC. For instance, the threshold pore diameter of the cores obtained at the center of slab with 1CC and $2 \mathrm{CC}$ were $50 \%$ and $22 \%$, respectively of the threshold pore diameter of cores with NC $(3.6 \mu \mathrm{m})$. Correspondingly, the proportion of micro-pores in these samples was more than 
$70 \%$ of the total pore volume (Table 7). This directly showed the pore structure refinement achieved by the application of curing compound (with marked difference between 1CC and $2 \mathrm{CC}$ ) to the pavement, at the joint area and center of slabs, resulting in efficient hydration reactions and better microstructural development. These trends allude to some insensitivity of the COW test (bulk absorption of concrete) in accurately evaluating the quality of microstructure of concrete at joint locations and distinctively differentiating between concretes with $1 \mathrm{CC}$ and $2 \mathrm{CC}$ at the center of slab.

In general, the BSEM observations at 180 days conformed to the results of the other tests at 28 days. For instance, as shown in Figure 9(a), the interfacial transition zone (ITZ) in field cores with NC shows scattered porous areas and some micro-cracks, which can be attributed to an insufficient level of hydration in this weak zone. Comparatively, notable densification and homogeneity are observed in the matrix at the ITZ of specimens from corresponding field cores with $1 \mathrm{CC}$ and $2 \mathrm{CC}$ [Figures 9(b)-(c)], due to the low w/b (0.360.38), incorporation of fly ash and application of curing compound at early-age. This trend is confirmatory to the MIP pore size distribution results, as corresponding specimens with NC had the highest total porosity and threshold pore diameter and the lowest percentage of micro-pores at 28 days (Table 7). The BSEM images signify the importance of early-age curing for efficient microstructural development of the cementitious matrix, and hence improved long-term performance of concrete pavements.

\section{Summary and Conclusions}

The effect of three different curing compound applications $(\mathrm{NC}, 1 \mathrm{CC}, 2 \mathrm{CC})$ on the transport properties and microstructural development of concrete pavements were investigated in this study. Based on the test procedures implemented in the current research, the following conclusions can be drawn:

- The general trend of the rate of absorption test (ASTM C1585 2013) showed some reduction of the total absorption of concrete with the application of curing compound (especially $2 \mathrm{CC}$ ) relative to $\mathrm{NC}$ due to the improvement in the hydration process near the surface of concrete. 
- For laboratory specimens and field cores obtained from the center of slab, the curing method had a significant effect on reducing the absorption ratio (COW test), conforming to the general trends of the ASTM C1585 test. The reduction of absorption capacity of concrete with $1 \mathrm{CC}$ and $2 \mathrm{CC}$ was due to the retention of moisture within the surface layer of concrete, which led to efficient hydration and microstructural development, with close performance of concrete with $1 \mathrm{CC}$ and $2 \mathrm{CC}$.

- In the COW test, the higher absorption values of the cores at the joints was attributed to increasing the exposed surface area in contact with water and weakened planes from the saw cutting operations at early- and later- ages. However, the dominant effect of the vertical faces of the cores made it difficult to distinctively reflect the quality of microstructure at joint locations, since high variability was observed among the results of different curing schemes.

- The RCPT results for laboratory and field concrete showed that specimens with 1CC and $2 \mathrm{CC}$ had slightly lower migration coefficients than that of corresponding specimens with NC, but without statistical significance. The low w/b $(0.36$ to 0.38$)$ of this concrete led to a dense and disconnected microstructure that decreased diffusion of chloride ions.

- The trends of TG, MIP and BSEM were confirmatory to that of the absorption and penetrability tests in the sense that there was better microstructural development of concrete and densification of the ITZ in the increasing order of $1 \mathrm{CC}$ and $2 \mathrm{CC}$, relative to corresponding concrete without curing (NC), even though the latter was exposed to intermittent rainfalls.

The overall results of this research indicate that applying $2 \mathrm{CC}$ is highly efficient at densifying concrete microstructure and reducing its absorption and penetrability, especially if the second coat properly covers joint walls resulting from saw-cutting. In addition, $2 \mathrm{CC}$ may be recommended for patch repairs which usually comprise vigorously reactive powders for efficient hydration. Adding $2 \mathrm{CC}$ will make it more difficult for curing compound surface to wear out due to attrition by vehicle tires, especially when quick opening to traffic is required. Whereas applying $1 \mathrm{CC}$ with visual inspection afterwards to cover 'holidays' at the surface of concrete pavement may lead to efficient microstructural development, applying 2CC maybe be more desirable from practical and technical perspectives . At joint locations, saw-cutting operations and lack of homogenous curing and 
drying of vertical surfaces within the joint seem to critically affect the pore structure characteristics and absorption capacity of concrete. This suggests that joints may benefit from an additional overfilling operation with a curing compound after saw-cutting, which can be applied with the second coat of curing.

\section{Acknowledgments}

The authors highly appreciate the financial support from Natural Sciences and Engineering Research Council of Canada, University of Manitoba and Public Works Department, City of Winnipeg. The new IKO Construction Materials Testing Facility at the University of Manitoba in which these experiments were conducted has been instrumental to this research.

\section{References}

AASHTO M148. 2005. Standard Specification for Liquid Membrane-Forming Compounds for Curing Concrete. American Association of State and Highway Transportation Officials, Washington, DC.

ACI 308R-16. 2016. Guide to External Curing of Concrete, American Concrete Institute, Farmington Hills, MI, 36 p.

Al-Gahtani, A.S. 2010. Effect of curing methods on the properties of plain and blended cement concretes. Construction and Building Materials, 24(3): 308-314.

ASTM C39/C39M. 2014. Standard Test Method for Compressive Strength of Cylindrical Concrete Specimens. ASTM International, West Conshohocken, PA.

ASTM C192/C192M. 2013. Standard Practice for Making and Curing Concrete Test Specimens in the Laboratory. ASTM International, West Conshohocken, PA.

ASTM C260. 2010. Standard Specification for Air-Entraining Admixtures for Concrete. ASTM International, West Conshohocken, PA. 
ASTM C309. 2011. Standard Specification for Liquid Membrane-Forming Compounds for Curing Concrete. ASTM International, West Conshohocken, PA.

ASTM C494/C494M. 2013. Standard Specification for Chemical Admixtures for Concrete. ASTM International, West Conshohocken, PA.

ASTM C1202. 2012. Standard Test Method for Electrical Indication of Concrete's Ability to Resist Chloride Ion Penetration. ASTM International, West Conshohocken, PA.

ASTM C1585. 2013. Standard Test Method for Measurement of Rate of Absorption of Water by Hydraulic-Cement Concretes. ASTM International, West Conshohocken, PA.

Bassuoni, M.T., Nehdi, M., and Greenough, T. 2006. Enhancing the reliability of evaluating chloride ingress in concrete using the ASTM C1202 rapid chloride penetrability test. Journal of ASTM International, 3(3): 1-13.

Bentz, D.P., and Jensen, O. 2004. Mitigation strategies for autogenous shrinkage cracking. Cement and Concrete Composites, 26(6): 677-685.

Bouzoubaâ N, Bilodeau A, Fournier, B., Hooton, R.D., Gagné, R., and Jolin, M. 2011. Deicing salt scaling resistance of concrete incorporating fly ash and (or) silica fume: laboratory and field sidewalk test data. Canadian Journal of Civil Engineering, 38(4): 373-382.

Chen, D, Lin, H., and Sun, R. 2011. Field performance evaluations of partial-depth repairs. Construction and Building Materials, 25(3): 1369-1378.

COW 2013-01. 2013. Standard Test Method for Measuring Absorption to Evaluate the Effectiveness of Curing Compound on Concrete Slabs and Adjoining Joints. City of Winnipeg, MB. 
CSA A23.1/A23.2. 2014. Concrete Materials and Methods of Concrete Construction/Test Methods and Standard Practices for Concrete. Canadian Standards Associations, CSA, Mississauga, ON.

CSA A3001. 2013. Cementitious Materials for Use in Concrete. Canadian Standards Associations, CSA, Mississauga, ON.

CW3310-R17. 2015. Portland Cement Concrete Pavement Works. City of Winnipeg, 24 p.

GCC (Government of Canada Climate). 2015. Government of Canada Climate Report, Government of Canada. Available from http://climate.weather.gc.ca/ [accessed 28 Nov. 2015].

GPDR-COW (Guide for Partial Depth Repair-City of Winnipeg). 2015. Guide for Partial Depth Repair of Concrete Pavements, Public Works Department Final Report, Winnipeg, MB, $21 \mathrm{p}$.

Ho, D., Cui, Q., and Ritchie, D.J. 1989. Influence of humidity and curing time on the quality of concrete. Cement and Concrete Research, 19(3): 457-464.

Ibrahim, M., Shameem, M., Al-Mehthel, M., and Maslehuddin, M. 2013. Effect of curing methods on strength and durability of concrete under hot weather conditions. Cement and Concrete Composites, 41: 60-69.

Kumar, R., and Bhattacharjee, B. 2003. Study on some factors affecting the results in the use of MIP method in concrete research. Cement and Concrete Research, 33(3): 417-424.

Liu, J., Xing, F., Dong, B., Ma, H., and Pan, D. 2014. Study on water sorptivity of the surface layer of concrete. Materials and Structures, 47(11): 1941-1951. 
Marchand, J., Sellevold, E., and Pigeon, M. 1994. The deicer salt scaling deterioration of concrete-An overview, ACI Special Publication SP-145, V.M. Malhotra Ed.,1-46.

MDOT (Michigan Department of Transportation) (1996) Research Record: Evaluating Pavement Patching Materials Polymers and Elastomeric Concretes. Michigan Department of Transportation Report RR-81, Chicago, IL, 4 p.

Mehta, P.K., and Monteiro, P.J.M. 2014. Concrete: Microstructure, Properties, and Materials. McGraw-Hill Education, New York, NY.

Montgomery, D. 2012. Design and Analysis of Experiments. John Wiley and Sons, Hoboken, NJ.

Nassif, H., Najm, H., and Suksawang, N. 2005. Effect of pozzolanic materials and curing methods on the elastic modulus of HPC. Cement and Concrete Composites, 27(6): $661-670$.

Neville, A.M. 2011. Properties of Concrete. Pearson, New York, NY.

NT BUILD 492. 1999. Chloride Migration Coefficient from Nonsteady-State Migration Experiments. NORDTEST, Finland.

Said, A., Zeidan, M.S., Bassuoni, M.T., and Tian, Y. 2012. Properties of concrete incorporating nano-silica. Construction and Building Materials, 36: 838-844.

Shi, D. and Winslow, D. 1985. Contact angle and damage during mercury intrusion into cement paste. Cement and Concrete Research, 15(4): 645-654.

TxDOT (Texas Department of Transportation) 2004. Standard Specifications for Construction and Maintenance of Highways, Streets, and Bridges. Texas Department of Transportation, Austin, TX. 
Vandenbossche, J.M. 1999. A Review of the Curing Compounds and Application Techniques Used by the Minnesota Department of Transportation for Concrete Pavements. Minnesota Department of Transportation Final Report MN/RC-200106, St. Paul, MN, 35 p.

\author{
List of notation \\ D is the non-steady-state migration coefficient \\ $D_{g} \quad$ is the dry mass of concrete \\ $I \quad$ is the absorption of concrete \\ $L \quad$ is the thickness of the specimen \\ $t \quad$ is time \\ $T \quad$ is the average value of initial and final temperatures in the anolyte solution \\ $V \quad$ is the applied voltage \\ $W A \quad$ is the percentage of water absorption of concrete \\ $W_{g} \quad$ is the wet mass of concrete \\ $x_{d} \quad$ is the average value of penetration depth
}


Table 1: Testing scheme for the field cores

\begin{tabular}{lccc}
\hline & \multicolumn{3}{c}{ No. and (diameter) of Field Cores } \\
\cline { 2 - 4 } Test & NC & $\mathbf{1 C C}$ & $\mathbf{2 C C}$ \\
\hline $\begin{array}{l}\text { Rate of Absorption } \\
\text { (ASTM C1585) }\end{array}$ & $8(100 \mathrm{~mm})$ & $8(100 \mathrm{~mm})$ & $8(100 \mathrm{~mm})$ \\
\hline $\begin{array}{l}\text { COW Test } \\
\text { (COW 2013-01) }\end{array}$ & $8(75 \mathrm{~mm})$ & $8(75 \mathrm{~mm})$ & $8(75 \mathrm{~mm})$ \\
\hline RCPT & $8(100 \mathrm{~mm})$ & $8(100 \mathrm{~mm})$ & $8(100 \mathrm{~mm})$ \\
\hline ASTM C1202) & $16(100 \mathrm{~mm})$ & $\begin{array}{c}16(100 \mathbf{m m}) \\
8(75 \mathbf{m m})\end{array}$ & $\begin{array}{r}16(100 \mathrm{~mm}) \\
8(75 \mathrm{~mm})\end{array}$ \\
\hline Total No. per section & $8(75 \mathrm{~mm})$ & $\mathbf{4 8 ( 1 0 0 ~ \mathbf { ~ m } )}$ \\
\hline
\end{tabular}

Table 2: Average results of the absorption test (ASTM C1585) for laboratory and field specimens

\begin{tabular}{|c|c|c|c|c|c|}
\hline \multirow[b]{2}{*}{ Source } & \multirow[b]{2}{*}{$\begin{array}{l}\text { Curing } \\
\text { Scheme }\end{array}$} & \multicolumn{2}{|c|}{ Initial } & \multicolumn{2}{|c|}{ Secondary } \\
\hline & & $\begin{array}{c}\text { Rate of } \\
\text { absorption } \\
\times 10^{-3} \\
\left(\mathbf{m m} / ل_{\mathbf{s}}\right)\end{array}$ & $\begin{array}{l}\text { Coefficient of } \\
\text { determination } \\
\left(\boldsymbol{R}^{2}\right)\end{array}$ & $\begin{array}{c}\text { Rate of } \\
\text { absorption } \\
\times 10^{-3} \\
(\mathrm{~mm} / \sqrt{ } \mathbf{s})\end{array}$ & $\begin{array}{r}\text { Coefficient of } \\
\text { determination } \\
\left(R^{2}\right)\end{array}$ \\
\hline \multirow{3}{*}{$\begin{array}{l}\text { Laboratory } \\
\text { Specimens }\end{array}$} & $\mathrm{NC}$ & 1.0 & 0.99 & 0.3 & 0.99 \\
\hline & $1 \mathrm{CC}$ & 1.1 & 0.99 & 0.4 & 0.99 \\
\hline & $2 \mathrm{CC}$ & 1.0 & 0.99 & 0.4 & 0.99 \\
\hline \multirow{3}{*}{$\begin{array}{l}\text { Cores at } \\
\text { Center }\end{array}$} & $\mathrm{NC}$ & 1.1 & 0.98 & 0.4 & 0.99 \\
\hline & $1 \mathrm{CC}$ & 1.1 & 0.99 & 0.4 & 0.99 \\
\hline & $2 \mathrm{CC}$ & 1.0 & 0.98 & 0.3 & 0.99 \\
\hline \multirow{3}{*}{$\begin{array}{l}\text { Cores } \\
\text { adjacent to } \\
\text { Joint }\end{array}$} & $\mathrm{NC}$ & 1.0 & 0.99 & 0.3 & 0.99 \\
\hline & $1 \mathrm{CC}$ & 1.0 & 0.99 & 0.3 & 0.99 \\
\hline & $2 \mathrm{CC}$ & 1.0 & 0.99 & 0.3 & 0.99 \\
\hline
\end{tabular}


Table 3: ANOVA for the results of ASTM C1585, COW and ASTM C1202 tests

\begin{tabular}{|c|c|c|c|c|c|}
\hline Test & Source & $\begin{array}{c}\text { Parameter } \\
\text { Tested } \\
\end{array}$ & $\boldsymbol{F}$ & P-Value & $\boldsymbol{F}_{c r}$ \\
\hline \multirow{3}{*}{$\begin{array}{l}\text { Rate of Absorption } \\
\text { (ASTM C1585) }\end{array}$} & Laboratory Specimens & & 3.32 & 0.1068 & 5.14 \\
\hline & Cores at Center & $\begin{array}{c}\text { Total } \\
\text { Absorption }\end{array}$ & 2.09 & 0.1792 & 4.26 \\
\hline & Cores adjacent to Joint & & 1.39 & 0.2984 & 4.26 \\
\hline \multirow{3}{*}{$\begin{array}{l}\text { COW Test } \\
(\text { COW 2013-01) }\end{array}$} & Laboratory Specimens & & $30.32^{*}$ & 0.0007 & 5.14 \\
\hline & Cores at Center & $\begin{array}{c}\text { Absorption } \\
\text { Ratio }\end{array}$ & $25.76^{*}$ & 0.0002 & 4.26 \\
\hline & Cores at Joint & & 0.68 & 0.5300 & 4.26 \\
\hline \multirow{3}{*}{$\begin{array}{l}\text { RCPT } \\
\text { (ASTM C1202) }\end{array}$} & Laboratory Specimens & & 5.12 & 0.0504 & 5.14 \\
\hline & Cores at Center & $\begin{array}{l}\text { Migration } \\
\text { Coefficient }\end{array}$ & 0.51 & 0.6148 & 4.26 \\
\hline & Cores adjacent to Joint & & 3.61 & 0.0704 & 4.26 \\
\hline
\end{tabular}

"Indicates statistical significance.

Table 4: Average water absorption (COW test) of laboratory and field specimens

\begin{tabular}{|c|c|c|c|c|c|}
\hline \multirow[b]{2}{*}{$\begin{array}{l}\text { Curing } \\
\text { Scheme }\end{array}$} & \multicolumn{2}{|c|}{ Laboratory Specimens } & \multicolumn{2}{|c|}{ Cores at Center } & \multirow{2}{*}{$\begin{array}{c}\begin{array}{c}\text { Cores at } \\
\text { Joint }\end{array} \\
\text { Absorption } \\
\text { Top } \\
(\%) \\
\end{array}$} \\
\hline & $\begin{array}{c}\text { Absorption } \\
\text { Top } \\
(\%) \\
\end{array}$ & $\begin{array}{c}\text { Absorption } \\
\text { Bottom } \\
(\%) \\
\end{array}$ & $\begin{array}{c}\text { Absorption } \\
\text { Top } \\
(\%) \\
\end{array}$ & $\begin{array}{c}\text { Absorption } \\
\text { Bottom } \\
(\%) \\
\end{array}$ & \\
\hline $\mathrm{NC}$ & 0.16 & 0.10 & 0.16 & 0.13 & 0.24 \\
\hline $1 \mathrm{CC}$ & 0.12 & 0.10 & 0.12 & 0.13 & 0.23 \\
\hline $2 \mathrm{CC}$ & 0.11 & 0.10 & 0.11 & 0.15 & 0.24 \\
\hline
\end{tabular}

Table 5: Absorption ratios and Tukey's test results for the COW test

\begin{tabular}{|c|c|c|c|c|c|c|}
\hline \multirow[b]{2}{*}{$\begin{array}{l}\text { Curing } \\
\text { Scheme } \\
\end{array}$} & \multicolumn{3}{|c|}{ Laboratory Specimens } & \multicolumn{3}{|c|}{ Cores at Center } \\
\hline & $\begin{array}{c}\text { Absorption } \\
\text { Ratio } \\
\end{array}$ & Difference & $q_{c r}$ & $\begin{array}{c}\text { Absorption } \\
\text { Ratio } \\
\end{array}$ & Difference & $q_{c r}$ \\
\hline $\mathrm{NC}$ & 1.58 & $0.39^{*}$ & & 1.25 & $0.36^{*}$ & \\
\hline $1 \mathrm{CC}$ & 1.20 & $0.53^{*}$ & 0.22 & 0.90 & $0.48^{*}$ & 0.20 \\
\hline $2 \mathrm{CC}$ & 1.05 & 0.15 & & 0.77 & 0.13 & \\
\hline
\end{tabular}

Indicates statistical significance. 
Table 6: Average passing charges (ASTM C1202), penetration depth, and migration coefficient for the top part of laboratory and field specimens

\begin{tabular}{|c|c|c|c|c|c|c|}
\hline \multirow[b]{2}{*}{ Source } & \multirow[b]{2}{*}{$\begin{array}{l}\text { Curing } \\
\text { Scheme }\end{array}$} & \multicolumn{2}{|c|}{ Charges } & \multicolumn{2}{|c|}{ Penetration } & \multirow{2}{*}{$\begin{array}{l}\text { Migration } \\
\text { Coefficient } \\
\left(\times 10^{-12} \mathrm{~m}^{2} / \mathrm{s}\right)\end{array}$} \\
\hline & & $\begin{array}{c}\text { Passing } \\
\text { (Coulombs) }\end{array}$ & $\begin{array}{l}\text { Standard } \\
\text { Deviation } \\
\end{array}$ & $\begin{array}{c}\text { Depth } \\
(\mathrm{mm})\end{array}$ & $\begin{array}{l}\text { Standard } \\
\text { Deviation } \\
\end{array}$ & \\
\hline \multirow{3}{*}{$\begin{array}{l}\text { Laboratory } \\
\text { Specimens }\end{array}$} & $\mathrm{NC}$ & 1765 & 119 & 13 & 0.4 & 12.0 \\
\hline & $1 \mathrm{CC}$ & 1665 & 29 & 12 & 0.8 & 11.0 \\
\hline & $2 \mathrm{CC}$ & 1658 & 114 & 11 & 0.5 & 10.0 \\
\hline \multirow{3}{*}{$\begin{array}{l}\text { Cores at } \\
\text { Center }\end{array}$} & $\mathrm{NC}$ & 1755 & 85 & 12 & 1.1 & 11.0 \\
\hline & $1 \mathrm{CC}$ & 1548 & 54 & 12 & 1.5 & 11.0 \\
\hline & $2 \mathrm{CC}$ & 1806 & 82 & 12 & 1.1 & 11.0 \\
\hline \multirow{3}{*}{$\begin{array}{l}\text { Cores } \\
\text { adjacent to } \\
\text { Joint }\end{array}$} & $\mathrm{NC}$ & 1864 & 56 & 12 & 0.9 & 11.0 \\
\hline & $1 \mathrm{CC}$ & 1798 & 28 & 11 & 0.3 & 10.0 \\
\hline & $2 \mathrm{CC}$ & 1813 & 114 & 10 & 0.5 & 9.0 \\
\hline
\end{tabular}

Note: all specimens had a 'low penetrability' class according to ASTM C1202.

Table 7: Mercury intrusion porosimetry (MIP) test results for field cores at 28 days

\begin{tabular}{lccccc}
\hline & Curing & $\begin{array}{c}\text { Total } \\
\text { Cumulative } \\
\text { Intrusion } \times \mathbf{1 0}^{-2} \\
(\mathbf{m l} / \mathbf{g})\end{array}$ & $\begin{array}{c}\text { Apparent } \\
\text { Total } \\
\text { Porosity } \\
(\mathbf{\%})\end{array}$ & $\begin{array}{c}\text { Threshold } \\
\text { Pore } \\
\text { Diameter } \\
(\boldsymbol{\mu m})\end{array}$ & $\begin{array}{c}\text { Proportion of } \\
\text { Micro-Pores } \\
(<\mathbf{0 . 1} \boldsymbol{\mu m})\end{array}$ \\
\hline \multirow{3}{*}{ Cores at Center } & NC & 6.0 & 13.5 & 3.6 & 67.7 \\
& $1 \mathrm{OC}$ & 5.6 & 12.2 & 1.8 & 70.8 \\
& $2 \mathrm{CC}$ & 4.8 & 11.3 & 0.8 & 74.1 \\
\hline \multirow{3}{*}{ Cores at Joint } & $\mathrm{NC}$ & 6.6 & 14.2 & 4.9 & 62.3 \\
& $1 \mathrm{CC}$ & 6.1 & 13.1 & 2.0 & 69.6 \\
& $2 \mathrm{CC}$ & 5.7 & 12.1 & 0.9 & 72.0 \\
\hline
\end{tabular}




\section{List of Figures}

Figure 1- Casting, finishing and curing operations for the field pavement sections.

Figure 2- A schematic diagram showing the locations of the cores extracted for the various tests.

Figure 3-Average daily temperature, relative humidity, precipitation and wind velocity data in Winnipeg for the period of 28 days from the day of casting (GCC 2015).

Figure 4-Rate of water absorption of concrete (ASTM C1585): (a) laboratory specimens, (b) cores at center, and (c) cores adjacent to joint.

Figure 5-Total water absorption (ASTM C1585) of laboratory and field specimens.

Figure 6-Absorption ratios (COW test) of laboratory and field specimens.

Figure 7-Whitish color showing the chloride front in the top part of laboratory specimens: (a) $\mathrm{NC}$, (b) $1 \mathrm{CC}$, and (c) $2 \mathrm{CC}$.

Figure 8-Thermogravimetry (TG) results for portlandite $(\mathrm{CH})$ contents in laboratory concrete at different ages.

Figure 9-BSEM micrographs of thin sections from the top part of field cores at mid slab at 180 days: (a) NC, (b) 1CC, and (c) 2CC. 


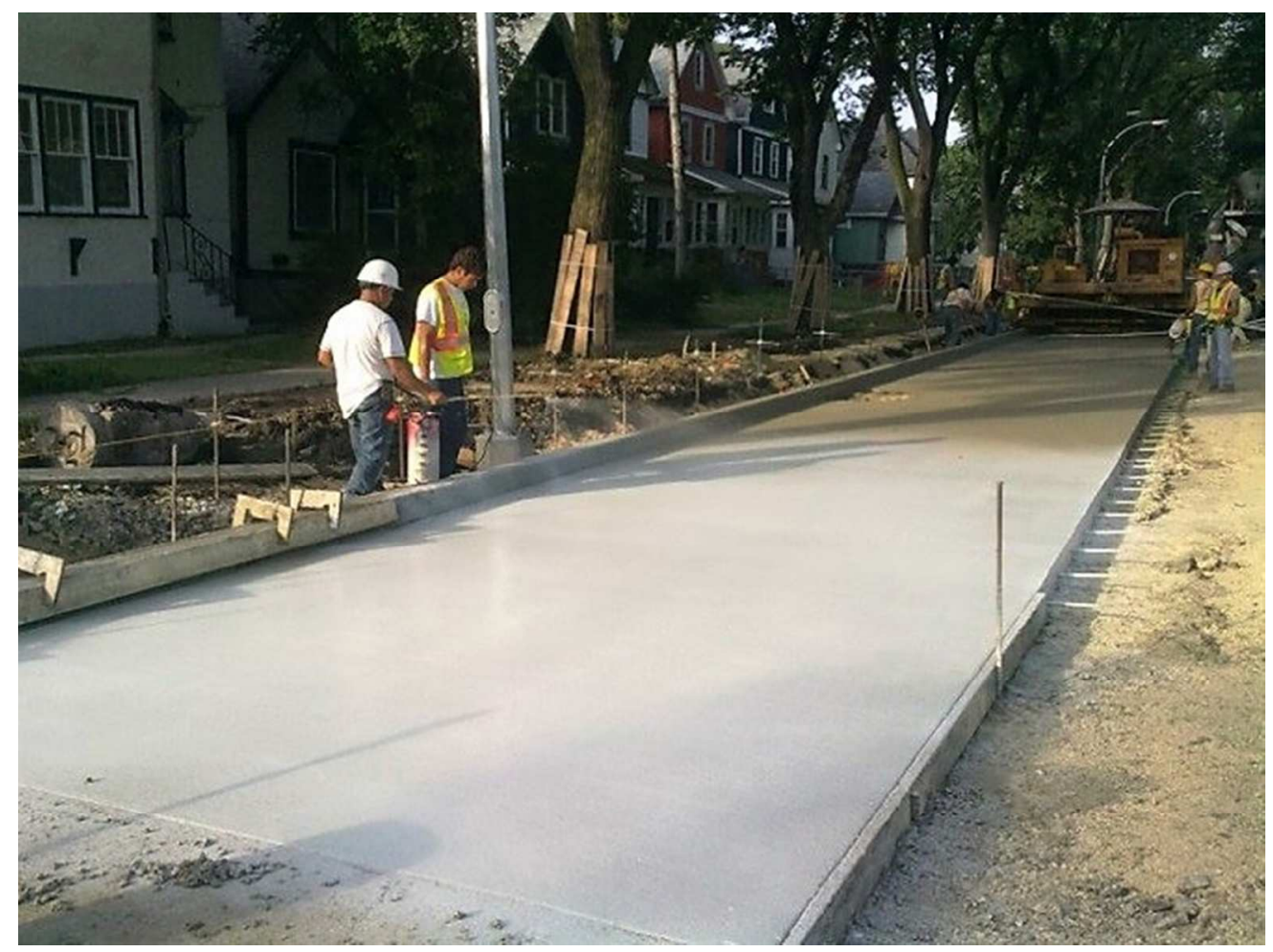

Figure 1- Casting, finishing and curing operations for the field pavement sections. $56 \times 42 \mathrm{~mm}(300 \times 300$ DPI $)$ 


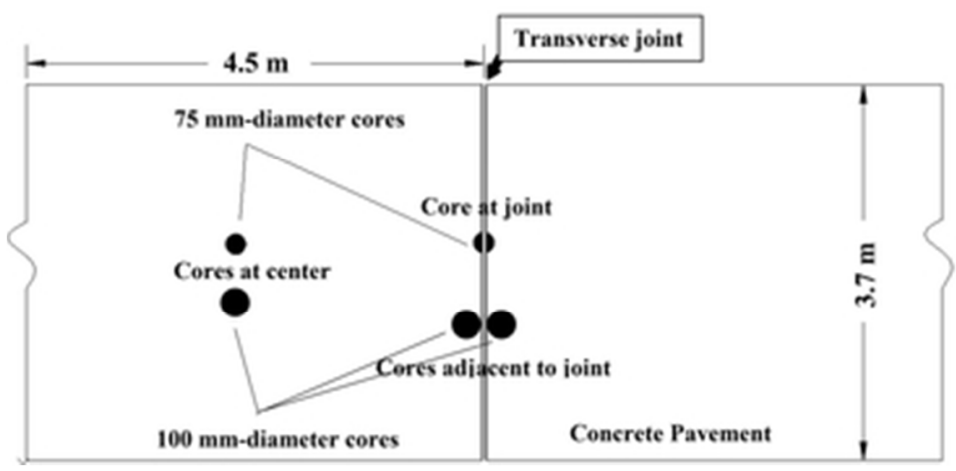

Figure 2- A schematic diagram showing the locations of the cores extracted for the various tests. $30 \times 14 \mathrm{~mm}(300 \times 300$ DPI $)$ 


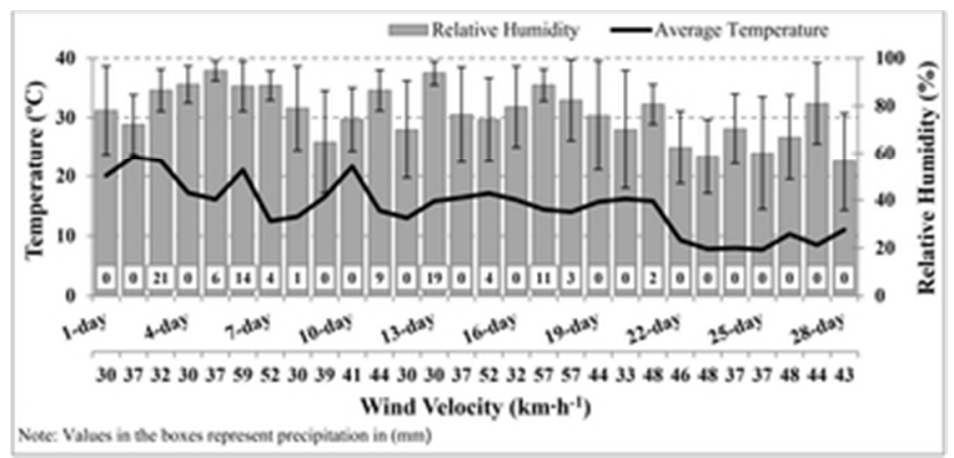

Figure 3-Average daily temperature, relative humidity, precipitation and wind velocity data in Winnipeg for the period of 28 days from the day of casting (GCC 2015).

$15 \times 7 \mathrm{~mm}(600 \times 600 \mathrm{DPI})$ 


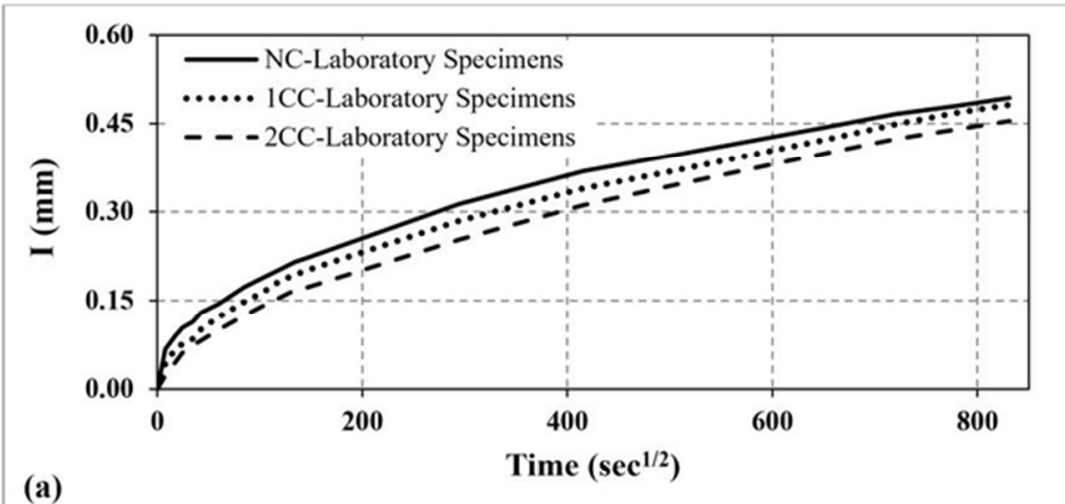

(a)
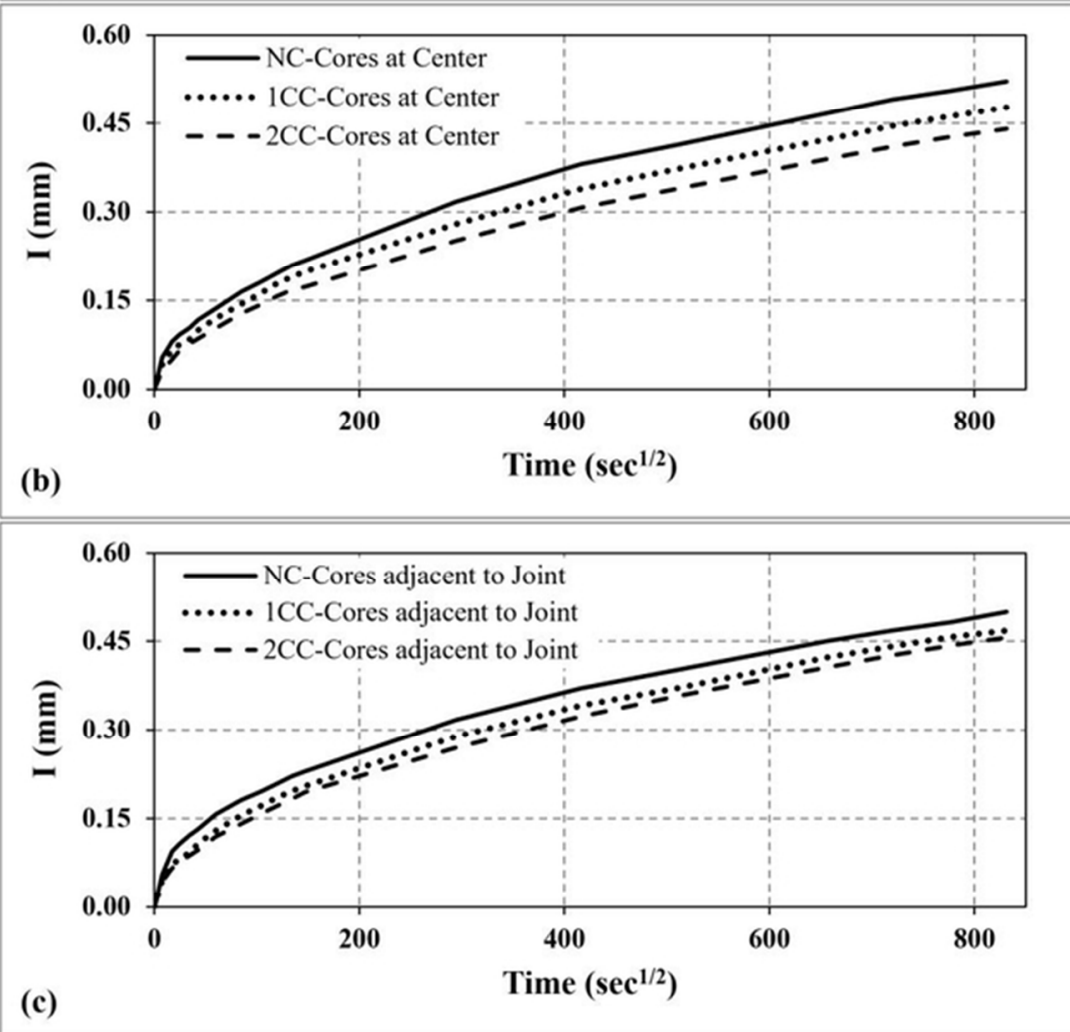

Figure 4-Rate of water absorption of concrete (ASTM C1585): (a) laboratory specimens, (b) cores at center, and (c) cores adjacent to joint.

$53 \times 76 \mathrm{~mm}(300 \times 300 \mathrm{DPI})$ 


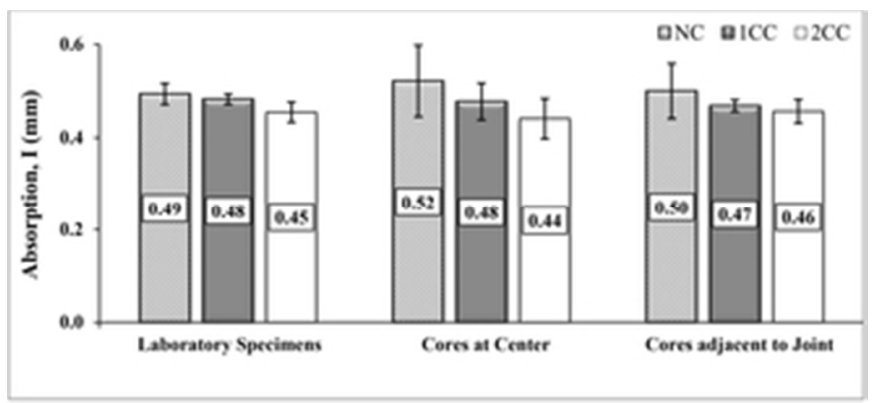

Figure 5-Total water absorption (ASTM C1585) of laboratory and field specimens. $13 \times 6 \mathrm{~mm}(600 \times 600 \mathrm{DPI})$ 


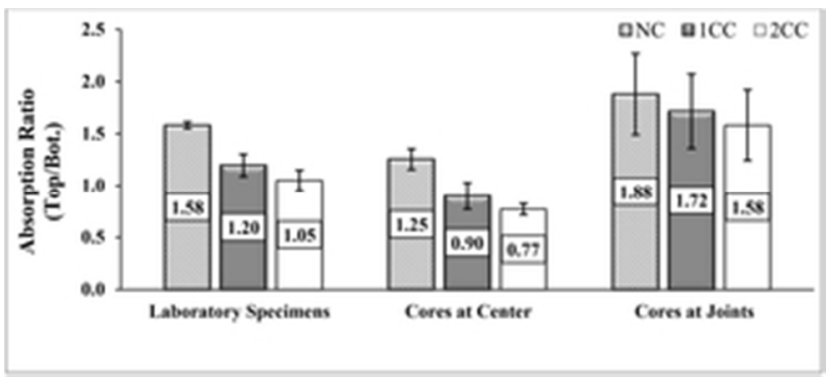

Figure 6-Absorption ratios (COW test) of laboratory and field specimens.

$13 \times 5 \mathrm{~mm}(600 \times 600 \mathrm{DPI})$ 

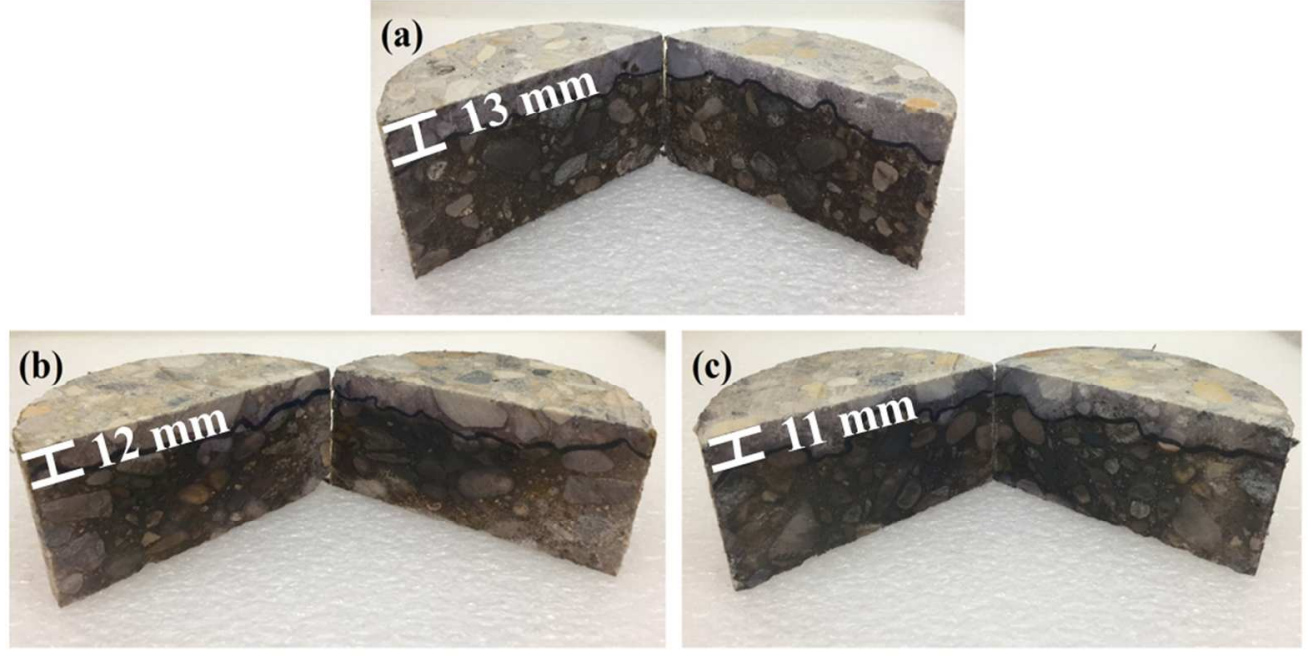

Figure 7-Whitish color showing the chloride front in the top part of laboratory specimens: (a) NC, (b) 1CC, and (c) 2CC. 


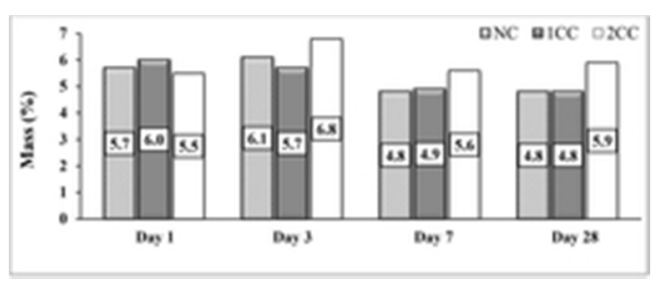

Figure 8-Thermogravimetry $(\mathrm{TG})$ results for portlandite $(\mathrm{CH})$ contents in laboratory concrete at different ages.

$10 \times 4 \mathrm{~mm}(600 \times 600 \mathrm{DPI})$ 

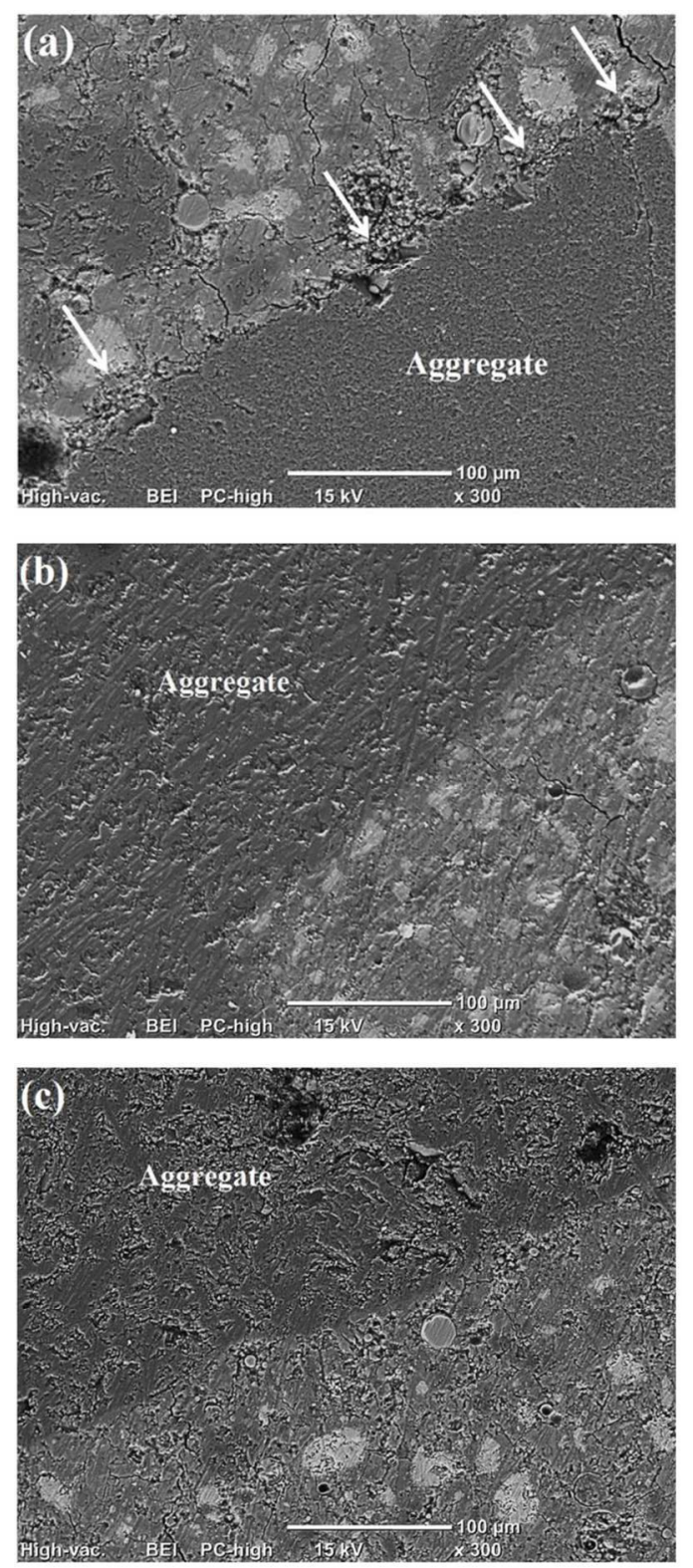

Figure 9-BSEM micrographs of thin sections from the top part of field cores at mid slab at 180 days: (a) NC, (b) $1 \mathrm{CC}$, and (c) $2 \mathrm{CC}$.

$58 \times 136 \mathrm{~mm}(300 \times 300$ DPI $)$ 